\title{
Collegio allemão de Pelotas-1923: cultura escolar e Deutschtum
}

\author{
German school of Pelotas - 1923: school culture and Deutschtum
}

Maria Angela Peter da Fonseca*

Universidade Federal de Pelotas

Elomar Antonio Callegaro Tambara**

Universidade Federal de Pelotas

Resumo Neste artigo contemplam-se especificidades da cultura escolar em um colégio teuto-brasileiro urbano, na década de 1920, em Pelotas, Rio Grande do Sul. A pesquisa realizada de forma quanti-qualitativa, bibliográfica, documental e por meio de entrevista, privilegia um aspecto descritivo, cuja fonte principal é o Relatório Escolar do Collegio Allemão de Pelotas de 1923. Através da análise de cinco tabelas apreendem-se dados relevantes de práticas culturais, desenvolvidas por um corpo docente masculino e feminino, direcionadas a um corpo discente misto, de descendentes de teuto-brasileiros, com a elaboração de um currículo ministrado 60\% em língua alemã, indicador da salvaguarda de um capital cultural denominado Deutschtum por meio da instituição escolar em tempos de Nacionalização do Ensino no Brasil, conjugando memória étnica com os valores emergentes da cidadania brasileira.

PALAVRAS-CHAVE: Collegio Allemão de Pelotas; Relatório Escolar 1923; Cultura Escolar.

Abstract In this article are contemplated specificities of school culture in an urban German School of Pelotas in the 1920s, in Pelotas, Rio Grande do Sul. The research was carried out in qualitative-quantitative way, bibliographical, documentary and through interview form, favoring a descriptive aspect, whose main source is the School Report of the German School of 1923. Through the analysis of five tables, was gathered relevant data of cultural practices, developed by male and female teachers, aimed at a mixed student body composed by descendants of German-Brazilians, with the development of a curriculum employed $60 \%$ in German language, safeguarding indicator of a cultural capital called Deutschtum through the educational institution in times of Education Nationalization in Brazil, combining ethnic memory with emerging values of Brazilian citizenship.

KEYWORDS: German School of Pelotas; School Report 1923; School Culture. 


\section{Palavras iniciais...}

A questão da educação escolar dos teuto-brasileiros, tanto rural como urbana, em nível de região e estado do Rio Grande do Sul tem sido privilegiada, sob diversos prismas, por muitos pesquisadores, tais como Kolling (2000), Fonseca (2007), Dreher (1984), Kreutz (1991 e 1994), Rambo (1994), Hoppen (1991), Meyer (2000) Garbosa (2003), Arendt (2005) entre outros. Podem-se citar, também, os trabalhos de Klug (1997) e Fiori (2003), em Santa Catarina, e os de Renk (2004) e Souza (2006), no Paraná. No entanto, há lacunas em relação à educação teuto-brasileira urbana no sul do Rio Grande do Sul, mais especificamente em Pelotas. E é preciso ter em mente que a cidade de Pelotas, está localizada em uma região caracterizadamente lusa onde a presença alemã representava um pequeno enclave num contexto multicultural. Num primeiro momento, houve a manutenção de uma tradição do ensino em língua alemã permitida e incentivada pelas lideranças do Partido Republicano Rio-Grandense que governavam o estado e viam com bons olhos o cuidado dos teuto-brasileiros com a educação. Posteriormente os ajustes necessários à implantação do processo de nacionalização do ensino, com vistas à constituição da nação brasileira, promoveram rupturas e aculturações nas instituições educacionais teuto-brasileiras.

De acordo com Quadros (2007) a atenção direcionada à nacionalização do ensino remonta aos primórdios da imigração, ainda no século XIX, devido à grande afluência e concentração de imigrantes alemães e italianos na região sul do Brasil, especialmente no Rio Grande do Sul. A isso somava-se a quase inexistência de escolas públicas, o que motivou os imigrantes a erigirem suas próprias escolas com o ensino ministrado no idioma de origem. Todavia a atenção sobre esses aspectos, intensificouse a partir dos anos de 1910 e da Primeira Guerra Mundial (1914-1918), encaminhando-se para uma abrangência em nível nacional, na década de 1930, cujo fio condutor foi a necessária obrigatoriedade do ensino em língua portuguesa, a subvenção federal para a construção de escolas, a supervisão estadual das escolas particulares e o fechamento de escolas, associações de naturezas diversas e jornais mantidos por estrangeiros. Segundo o mesmo autor (2007) o discurso da nacionalização do ensino foi elaborado a partir da necessidade da formação de um espírito nacional e da homogeneização de um território de múltiplas culturas, fazendo-se urgente em função do risco da influência de políticas estrangeiras junto às escolas étnicas no sul do Brasil. Discurso esse, legitimado através de publicações e notícias em jornais e, também, da emblemática conferência do Secretário da Educação, do Rio Grande do Sul, Coelho de Souza, na Associação Brasileira de Educação, em 1941, no Rio de Janeiro, seguida de sua publicação com o título "Denúncia: o nazismo nas escolas do Rio Grande".

Porém, "a nacionalização do ensino abriu um campo de possibilidades para a atuação do Estado no âmbito educacional no Rio Grande do Sul, que até então se restringia a poucos atos administrativos e muito incipientes iniciativas de aperfeiçoamento técnico ou pedagógico" (QUADROS, 2007, p. 6). Esse momento de rupturas, para além de oferecer condições materiais e efetuar a contratação de pessoal docente e técnico-administrativo, trouxe uma orientação e, principalmente, uma direção de longa duração para a educação pública no Rio Grande do Sul, a partir de matrizes conceituais da Escola Nova que se encontravam em efervescência na Europa e nos 
Estados Unidos desde o final do século XIX, fazendo-se presentes no Brasil através de políticas educacionais públicas do Estado Novo. No entanto, sob o viés do ensino particular no Rio Grande do Sul, especificamente nas instituições educacionais teuto -brasileiras, o movimento de nacionalização do ensino promoveu uma aculturação em massa nos educandários que permaneceram abertos, uma vez que o ethos étnico era transmitido através do canto, da literatura, entre outros conhecimentos, todos ministrados em língua alemã. Consequentemente, na impossibilidade da continuidade de relações interculturais e manutenção de culturas originais, houve perdas irreversíveis na cultura escolar, promovidas por alterações nos currículos das escolas teuto-brasileiras a partir da década de 1930.

\section{Collegio Allemão de Pelotas}

O Collegio Allemão de Pelotas, um colégio urbano, de ensino primário e secundário, para meninos e meninas, foi fundado em 1898, na cidade de Pelotas, na região sul do Rio Grande do Sul, por uma sociedade escolar cujos membros eram imigrantes alemães e teuto-brasileiros, industriais e comerciantes, em sua maioria evangélicos luteranos, que pertenciam à Comunidade Evangélica Alemã de Pelotas, filiada ao Sínodo Rio-Grandense ${ }^{1}$, cujas alianças se tornaram visíveis através da presença dos primeiros diretores do Collegio Allemão de Pelotas: os pastores Naumann, Weller e Sudhaus. Porém, em 1907, o professor André Gaile assumiu a direção do educandário, sendo substituído pelo professor Reinhard Heuer em 1916, anunciando mudanças para os próximos anos de funcionamento. Nesse interim, a instituição, inicialmente vinculada aos ideais religiosos através dos primeiros diretores e da sociedade escolar, rompeu com os interesses da igreja apresentando um perfil de laicidade. Isso é explicitado no artigo primeiro dos Estatutos do Collegio Allemão de Pelotas de 1915.

O fim do Collegio Allemão é o de implantar por intermédio da instrução subministrada nos idiomas allemão e do Paiz, os costumes da pátria, e sua intenção, como também de preparar seus discípulos até o necessário para a realização de seus direitos de cidadão e conhecimentos profissionais na nova pátria. No caso de se tornar de interesse para o collegio, poderá o mesmo receber a autorisação de estender certificados de habilitação, os quaes dão o direito para o serviço militar obrigatório na Allemanha, como aspirantes a officiaes. Far-se-á o possível para a realização desse propósito. O ensino constará, portanto de dois idiomas, até o pleno conhecimento dos mesmos, aspirando a instituição os limites de um collegio de media cathegoria, mas sem consideração aos interesses communs da igreja ou da classe social. (ESTATUTOS DO COLLEGIO ALLEMÃO DE PELOTAS, 1915).

Os estatutos deixam claro que havia uma orientação pedagógica diferenciada, aliada à inserção de jovens no mercado de trabalho, mas realizando seus direitos de cidadãos na nova pátria. $\mathrm{E}$, curiosamente, o colégio poderia estender certificados de habilitação, aos alunos do sexo masculino, o que daria direito ao serviço militar obrigatório na Alemanha. Através do artigo primeiro desses estatutos, é possível elencar elementos que caracterizavam a instituição, como por exemplo: o ensino em dois idiomas, a preocupação com a preparação dos alunos para inserção na nova pátria, com vistas à 
garantia dos direitos de cidadão, os conhecimentos profissionais, o serviço militar no estrangeiro, as aspirações da instituição, a igreja e a classe social.

Em 1920 o Collegio Allemão de Pelotas, em seu 22․ ano de funcionamento, veicula em jornal local a mudança de nome para Collegio Internacional. Nessa nota, informa-se a reabertura do ano letivo e enfatiza a importância do ensino da língua vernácula, dando um novo lugar à língua alemã, dessa vez, como língua estrangeira, ao lado do francês e do inglês. É dado destaque à erudição do diretor da instituição: professor Reinhard Heuer, autor de vários livros do ensino primário, bem como à qualificação do corpo docente.

Collegio Internacional

O Collegio Allemão, fundado em 1898 reabre as suas aulas no dia 2 de fevereiro de 1920, sob o nome supra, começando assim o $22^{\circ}$. ano. O ensino será ministrado na língua portugueza e conforme aos princípios mais modernos. $\mathrm{O}$ estabelecimento tem por fim formar os seus alumnos pelo ensino individual, principalmente para a vida prática. Por isso dá-se a maior importância fóra do ensino da língua vernácula à Arithmetica e Geographia, às línguas estrangeiras (francez, allemão e inglez). O ensino é ministrado por professores formados em pedagogia sob a direcção do professor R. Heuer autor de varios livros de ensino primario. Mais informações dará o director do collegio, á rua Felix da Cunha 761, nos dias úteis das 9 ás 11 horas. (O REBATE, 1920, p. 5).

No que diz respeito ao conhecimento do diretor e dos professores ${ }^{2}$ do Collegio Allemão de Pelotas, nesse período acima mencionado, Johanna Ritter Ruge Hofmeister com 92 anos, a única aluna encontrada, mencionou que o diretor Reinhard Heuer escreveu uma gramática em alemão e, complementou, com entusiasmo: "Nunca vi gramática melhor do que essa” (2002). Johanna ingressou no educandário logo após à publicação dos Estatutos de 1915, acima citados, e concluiu seus estudos no ano da veiculação da nota do Rebate de 1920. Diz ter entrado direto no segundo ano uma vez que foi alfabetizada em casa. De acordo com seu testemunho todo o ensino na instituição era em alemão. No entanto, na nota do jornal a língua alemã ocupa o status de língua estrangeira. A partir desses dados questionamos qual era a cultura escolar que circulava dentro do educandário em relação às agregações da língua alemã? Ela continuava sendo a língua do ensino cotidiano ou ajustava-se gradativamente ao processo de nacionalização do ensino? $\mathrm{Na}$ sequência questiona-se: qual o impacto causado na formação dos alunos do Collegio Allemão de Pelotas ao receberem aulas ministradas em alemão dentro de uma sociedade predominantemente luso-brasileira? E como a língua alemã veiculou o conhecimento cultural desse grupo étnico? Para Chervel (1990), o sistema escolar é investido de um poder criativo que é exercido na relação que a escola mantém com a sociedade, com a função de formar indivíduos, impactando diretamente a vivência deles em sociedade, ou seja, "forma não somente os indivíduos, mas também uma cultura que vem por sua vez penetrar, moldar, modificar a cultura da sociedade global". (CHERVEL, 1990, p. 184). E ao analisar a história das disciplinas escolares, concebe uma disciplina como um modo de disciplinar o espírito, utilizando métodos e regras para trabalhar os diversos domínios do pensamento, do conhecimento e da arte, contribuindo dessa forma para o entendimento da cultura que é produzida na e pela escola. 


\section{Relatório Escolar do Collegio Allemão de Pelotas do ano de 1923}

Três anos depois, por ocasião da comemoração dos vinte e cinco anos do colégio, o diretor Reinhard Heuer, elaborou e assinou uma edição comemorativa denominada: In Zum 25 jährigen Bestehen der Deutschen Schule zu Pelotas, 1898-1923 (Vinte e Cinco Anos de Existência da Escola Alemã de Pelotas, 1898-1923). Trata-se de um pequeno livro de 22 páginas, escrito em língua alemã e impresso na Livraria Rio-Grandense, em Rio Grande, no qual se encontra o Relatório Escolar do Collegio Allemão de Pelotas de 1923, principal fonte desse texto. Através da análise do Relatório Escolar de 1923 em que contemplamos o estudo de cinco tabelas correspondentes, respectivamente à carga horária dos professores, à carga horária de cada disciplina, ao número total de alunos em 1923, à nacionalidade dos alunos e ao número total de alunos nos últimos anos (1911-1923), foi possível apreender dados significativos em relação ao corpo docente, ao currículo e ao corpo discente da instituição em 1923. O Collegio Allemão de Pelotas era mantido por uma sociedade escolar que, nesse ano, compunha-se dos seguintes senhores: Carlos Ritter $^{3}$, membro de honra da diretoria; Friedrich Ruge ${ }^{4}$, presidente; A. Doormann, Vice-Presidente; O. Bratenahl, Tesoureiro; F. Peschlow, $1^{\circ}$ Secretário; J.v. d. Heyde, 2 Secretário; A. Schwab e W. Nelle, vogais e Reinhard Heuer, diretor desde 1916. O ensino completo constava de quatro classes de duplos, ou seja, a cada classe correspondiam dois anos. Por exemplo: a quarta classe era integrada pelo primeiro e o segundo ano; a terceira classe compunha-se do terceiro e do quarto ano; a segunda classe: o quinto e o sexto ano e, finalmente, a primeira classe: o sétimo e oitavo ano. No entanto, nesse ano o colégio ofereceu ensino somente da terceira à primeira classe, respectivamente, do terceiro ao oitavo ano. De acordo com o relatório, a quarta classe, do primeiro e do segundo ano, não funcionou. $\mathrm{O}$ relatório não apresenta justificativa para essa exclusão. Passaremos, então, a descrever e analisar as cinco tabelas.

\section{Corpo docente}

Através da análise da tabela 1: Vista geral da divisão de horas de cada um dos professores (Übersicht über die Stundenverteilung auf die einzelnen Lehrkräfte) referente à distribuição da carga horária dos professores, tivemos acesso ao corpo docente e ao currículo do Collegio Allemão de Pelotas, no ano de 1923. Damos destaque à carga horária e às disciplinas ministradas pelos professores, contempladas nesta estatística. O corpo docente compunha-se dos seguintes professores: diretor e professor Reinhard Heuer, com 36 horas/aula semanais (33,9\%); professora Marília Siqueira, com 32 horas/aula semanais (30,1\%); professor Wintersberger, com 32 horas/aula semanais $(30,1 \%)$ e professora Fräulein (Senhorita) Schalli, com 2 horas para três classes (5,9\%). A soma da carga horária de todos os professores chegava a 106 horas semanais. A partir destes dados, constatamos que $64 \%$ da carga horária curricular estava nas mãos de dois professores: do diretor e professor Reinhard Heuer e do professor Wintersberger. O restante da carga horária, correspondente a 36\%, ficava a cargo de duas professoras: Marília Siqueira e Schalli. 
Tabela 1 - Vista Geral da Divisão de Horas de cada um dos Professores (Übersicht über die Stundenverteilung auf die einzelnen Lehrkräfte) (RELATÓRIO ESCOLAR DO COLLEGIO ALLEMÃO DE PELOTAS, 1923, p. 17).

Überficht über die Stundenverteilung auf die einzelnen Lehrkräfte.

\begin{tabular}{|c|c|c|c|c|}
\hline Lehrer & 3. Klasse & 2. Klasse & 1. Klasss & $\begin{array}{l}\text { Conterrichts- } \\
\text { stunden }\end{array}$ \\
\hline Heuer, Direktor & & $\begin{array}{l}6 \text { Deutsch } \\
2 \text { Geographie }\end{array}$ & \begin{tabular}{ll|}
6 & Deutsch \\
4 & Rechnen \\
2 & Geometrie \\
2 & Chorographia \\
2 & Französisch \\
4 & Englisch \\
2 & Geographie \\
3 & Weltgeschichte \\
2 & Naturgeschichte \\
1 & Physik \\
\end{tabular} & 36 \\
\hline $\begin{array}{l}\text { D. Marilia } \\
\text { Siqueira }\end{array}$ & $\begin{array}{ll}6 & \text { Portugiesisch } \\
2 & \text { Schreiben } \\
3 & \text { Liçues de cousas } \\
2 & \text { Zeichnen } \\
\end{array}$ & $\begin{array}{|ll|}7 & \text { Portugiesisch } \\
2 & \text { Histuria Patria } \\
2 & \text { Zeichnen } \\
2 & \text { Schreiben } \\
\end{array}$ & 6 Portugiesisch & 32 \\
\hline Wintersberger & $\begin{array}{|ll|}7 & \text { Deutsch } \\
6 & \text { Rechnen } \\
3 & \text { Schreiben } \\
2 & \text { Zeichnen } \\
1 & \text { Gesang } \\
\end{array}$ & \begin{tabular}{l|}
6 Rechnen \\
2 Naturgesthichte \\
2 Schreiben \\
1 Bibl. anschichte:
\end{tabular} & 2 Zeichnen & 32 \\
\hline Fräulein Schalli & \multicolumn{3}{|c|}{2 Handarbeit } & 2 \\
\hline
\end{tabular}

O professor Reinhard Heuer ministrava aulas em duas classes. Na primeira classe (7॰ e e $8^{\circ}$. ano), 6 horas de Alemão, 4 horas de Matemática, 2 horas de Geometria, 2 horas de Chorografia, 2 horas de Francês, 4 horas de Inglês, 2 horas de Geografia, 3 horas de História Geral, 2 horas de História Natural, 1 hora de Física. Na segunda classe (5․ e $6^{\circ}$. ano), lecionava 6 horas de Alemão e 2 horas de Geografia. A professora Marília Siqueira lecionava em três classes. Na primeira classe, 6 horas de Português. Na segunda classe, 7 horas de Português; 2 horas de História Pátria; 2 horas de Desenho; 2 horas de Escrita. Na terceira classe ( $3^{\circ}$. e $4^{\circ}$. ano), lecionava 6 horas de Português, 2 horas de Escrita, 3 horas de Lições de Coisas, 2 horas de Desenho. O professor Wintersberger ministrava aulas em três classes. $\mathrm{Na}$ primeira, 2 horas de Desenho. $\mathrm{Na}$ segunda, 6 horas de Matemática, 2 horas de História Natural, 2 horas de Escrita e 1 hora de História Bíblica. Na terceira classe, lecionava 7 horas de Alemão, 6 horas de Matemática, 3 horas de Escrita, 2 horas de Desenho e 1 hora de Canto. A professora Schalli era responsável pelos trabalhos manuais em todos os anos das três classes, com 2 horas em cada classe. Enquanto que a presença da professora Marília Siqueira no corpo docente do Collegio Allemão de Pelotas, em 1923, vinculava-se à necessidade de o colégio disponibilizar uma professora brasileira para ministrar, especialmente, o Português e a História Pátria.

A docência ocupada por duas professoras que integravam o corpo docente do Collegio Allemão de Pelotas, ministrando aulas de trabalhos manuais e aulas em Português entre outras disciplinas, evidencia o status feminino, que, segundo Tambara (2002, p 67), indica para a feminização do magistério gaúcho, através da qualificação profissional. No entanto, também aponta para a feminilização do magistério, em contraposição à desqualificação profissional, sofrida no início do século XX, não sendo, 
portanto, sinônimo de prestígio econômico, a despeito do valor social e educacional. Apesar de ser uma escola eminentemente germânica, o ensino do Português e da História Pátria era altamente significativo quando desenvolvido por um professor brasileiro, uma vez que através da língua portuguesa, seria transmitido um modo de ser brasileiro. A importância dessas disciplinas pode ser comparada a uma porta de acesso a um entorno que contém uma instituição étnica. A visão de mundo que estava sendo construída na mente e no modo de ser dos alunos estava pautada na relação dos contrastes, caracterizada pelo choque entre culturas, em um colégio predominantemente alemão, em solo brasileiro. Nesse ano, através do plano curricular, percebe-se que não foi oferecido o ensino para a quarta classe $\left(1^{\circ}\right.$. e $2^{\circ}$. ano).

\section{Currículo}

Na tabela 2, intitulada: Vista geral do Horário Semanal nos seus pormenores sobre a carga horária de cada disciplina, (Übersicht der Wochenstunden auf die einzelnen Lehrgegenstände) identificamos as disciplinas que compunham o horário semanal e damos continuidade ao estudo iniciado na tabela 1 , referente ao currículo do Collegio Allemão de Pelotas, do ano de 1923 . Ao currículo da terceira classe ( $3^{\circ}$. e $4^{\circ}$. ano) correspondiam nove disciplinas: Anschaunngsunterricht (Ensino Visual), Portugiesisch (Português), Deutsch (Alemão), Rechnen (Matemática), Lições de Coisas, Schreiben (Escrita), Zeichnen (Desenho), Singen (Canto), Handarbeit (Trabalhos Manuais). Em relação à segunda classe $\left(5^{\circ}\right.$. e $6^{\circ}$. ano) dez disciplinas compunham o currículo: Portugiesisch (Português), Deutsch (Alemão), Rechnen (Matemática), História Pátria, Biblische Geschichte (História Bíblica), Geographie (Geografia), Naturgeschichte (História Natural), Schreiben (Escrita), Zeichnen (Desenho), Handarbeit (Trabalhos Manuais).

Tabela 2-Vista Geral do Horário Semanal nos seus pormenores sobre a carga horária de cada disciplina (Übersicht der Wochenstunden auf die einzelnen Lehrgegenstände) (RELATÓRIO ESCOLAR DO COLLEGIO ALLEMÃO DE PELOTAS, 1923, p. 17).

Überficht der Wochenitunden auf die einzelnen Lehrgegenitände.

\begin{tabular}{|c|c|c|c|c|}
\hline Lehrgegenstände & 3. Klasse & 2. Klasse & 1. Klasse & Unterrichtssprache \\
\hline $\begin{array}{l}\text { Anschauungsunterricht } \\
\text { Portugiesisch } \\
\text { Deutsch } \\
\text { Rechnen } \\
\text { Geometrie } \\
\text { Französisch } \\
\text { Englisch } \\
\text { Liçôes de cousas } \\
\text { Historia Patria } \\
\text { Chorographia do Brasil } \\
\text { Biblische Geschichte } \\
\text { Geographie } \\
\text { Naturgeschichte } \\
\text { Weltgeschichte } \\
\text { Physik } \\
\text { Schreiben } \\
\text { Zeichnen } \\
\text { Singen } \\
\text { Handarbeit } \\
\end{array}$ & $\begin{array}{l}3 \\
6 \\
6 \\
6 \\
- \\
- \\
3 \\
\\
\\
\\
\\
\\
5 \\
2 \\
1 \\
2 \\
\end{array}$ & \begin{tabular}{|l|}
$\overline{7}$ \\
6 \\
6 \\
$\overline{-}$ \\
$\overline{-}$ \\
$\frac{2}{2}$ \\
1 \\
$\frac{2}{2}$ \\
$\frac{4}{2}$ \\
$\frac{2}{2}$ \\
\end{tabular} & $\begin{array}{l}\overline{6} \\
6 \\
4 \\
2 \\
2 \\
4 \\
\overline{-} \\
\overline{2} \\
\overline{2} \\
\frac{2}{3} \\
\frac{1}{2} \\
\frac{2}{2} \\
\end{array}$ & \begin{tabular}{|c|} 
deutsch \\
portugiesisch \\
deutsch \\
deutsch u. portug. \\
deutsch \\
portugiesisch \\
deutsch \\
poitugiesisch \\
portugiesisch \\
portugiesisch \\
deutsch \\
deutsch \\
deutsch \\
deutsch \\
deutsch \\
deutsch u. portug. \\
deutsch u. portug. \\
deutsch \\
deutsch \\
\end{tabular} \\
\hline & $32+2 *$ & $\left|32+2^{*}\right|$ & $36+2^{*}$ & \\
\hline
\end{tabular}

*) +2 Handarbeitsstunden, die. am schulfreien Nachmittag erteilt werden. 
Finalmente, treze disciplinas integravam o currículo da primeira classe (7॰. e $8^{\circ}$. ano): Portugiesisch (Português), Deutsch (Alemão), Rechnen (Matemática), Geometrie (Geometria), Französisch (Francês), Englisch (Inglês), Chorographia do Brasil (Corografia do Brasil), Geographie (Geografia), Naturgeschichte (História Natural), Weltgeschichte (História Geral), Physik (Física), Zeichnen (Desenho), Handarbeit (Trabalhos Manuais). Cinco disciplinas formavam o núcleo central do currículo de 1923, isto é, eram comuns a todos os anos: Portugiesisch (Português, 19h), Deutsch (Alemão, 18h), Rechnen (Matemática, 16h), Zeichnen (Desenho, 6h) e Handarbeit (Trabalhos Manuais, 6h). Correspondendo a 61,3\% do espaço do currículo, equivalentes a uma soma de 65 horas, abrangiam pouco mais do que a metade da carga horária total. Essas disciplinas tinham o objetivo de contemplar a educação do aluno como um todo.

\section{Corpo discente}

Com o objetivo de apresentar características dos alunos que frequentaram o Collegio Allemão no ano de 1923, analisamos três tabelas, correspondentes ao número total de alunos nas classes únicas em 1923, à nacionalidade dos alunos e ao número total de alunos de 1913 a 1923 . Na tabela 3 que contempla a vista geral sobre o número total de alunos nas classes únicas em $1^{\circ}$. de julho de 1923 (Übersicht über die Schülerzabl in den einzelnen Klassen am 1.Juli 1923) encontra-se o número total de alunos, divididos por classe e sexo. A terceira classe, que correspondia ao $3^{\circ}$. e $4^{\circ}$. ano, com 32 alunos, sendo 18 meninos e 14 meninas, abrangia $47,7 \%$ do total de alunos. $\mathrm{Na}$ segunda classe, ou seja, $5^{\circ}$. e $6^{\circ}$. ano, 23 alunos frequentavam as aulas, sendo 13 meninos e 10 meninas, representando $34,3 \%$ do total. Na primeira classe, do $7^{\circ}$. e $8^{\circ}$. ano, apenas 12 alunos integravam o corpo discente, sendo 7 alunos e 5 alunas, num escore de $17,9 \%$ do total. O maior número de alunos estava concentrado na terceira classe, o menor número de alunos frequentava a primeira classe. A proporção entre meninos e meninas era de $56 \%$ para $47 \%$.

Tabela 3 -Vista Geral sobre o Número Total de Alunos nas Classes Únicas em 1 de julho de 1923 (Übersicht über die Schülerzahl in den einzelnen Klassen am 1.Juli 1923) (RELATÓRIO ESCOLAR DO COLLEGIO ALLEMÃO DE PELOTAS, 1923, p. 16).

\section{Überficht über die Schülerzahl in den einzelnen Klassen} am 1. Juli 1923.

\begin{tabular}{l|c|c|c|c}
\hline & Klasse 3 & Klasse 2 & Klasse 1 & Summe \\
\hline Knaben & 18 & 13 & 7 & 38 \\
Mädchen & 14 & 10 & 5 & 29 \\
\hline & 32 & 23 & 12 & 67 \\
\hline
\end{tabular}

A tabela 4: vista geral sobre a nacionalidade em $1^{\circ}$. de julho de 1923 (Übersicht über die Staatsangebörigkeit am 1. Juli 1923) privilegia três aspectos: a nacionalidade dos pais, a língua falada nas famílias e a religião. Em relação à origem étnica dos pais, 61 crianças eram teuto-brasileiras, duas latino-brasileiras, uma suíça, uma holan- 
desa, uma austríaca e uma inglesa. As crianças teuto-brasileiras constituíam a maioria do corpo discente, atingindo um total de $91 \%$. As demais crianças representavam $9 \%$ do total. A respeito da língua materna falada pelas crianças, evidencia-se que 95,5\% dos alunos, ou seja, 64 crianças, falavam a língua alemã em casa. Há indícios de que as crianças falassem dialetos alemães em suas famílias, como por exemplo, o pomerano, vindo a aprender a língua alemã padrão, somente no colégio. Das outras crianças, representando $4,5 \%$ do total de alunos, uma falava o inglês e duas falavam o português. Sobre a religião dos alunos, 61 crianças eram evangélicas, abrangendo $91 \%$ do total. Entre estas crianças, 58 eram teuto-brasileiras, uma suíça e uma holandesa. Em relação às seis crianças católicas, três eram teuto-brasileiras, duas latino-brasileiras e uma austríaca, alcançando $9 \%$ do total. A criança inglesa não está inserida em nenhuma das denominações, apesar de estar contada no escore final.

Tabela 4- Vista Geral sobre a Nacionalidade em 1 de julho de 1923 (Übersicht über die Staatsangehörigkeit am 1. Juli 1923) (RELATÓRIO ESCOLAR DO COLLEGIO ALLEMÃO DE PELOTAS, 1923, p. 16).

Überficht über die Staatsangehörigkeit am 1. Juli 1923.

\begin{tabular}{|c|c|c|c|c|c|}
\hline \multirow{2}{*}{ Staatsangehörigkeit } & \multirow{2}{*}{ Zahl } & \multicolumn{2}{|c|}{ Muttersprache } & \multicolumn{2}{|c|}{. Religion } \\
\hline & & deutsch & | nicht deutsch. & katholiscli & evangeliscll \\
\hline $\begin{array}{l}\text { Reichsildutsche rinschliesslich } \\
\text { Dentsch-Brasilier }\end{array}$ & 61 & 61 & - & 3 & 58 \\
\hline Latino-Brasilier & 2 & - & 2 & 2 & - \\
\hline Schweizer & 1 & 1 & - & - & 1 \\
\hline Holländer & 1 & 1 & - & - & 1 \\
\hline Osterreicher & 1 & 1 & - & $1 /$ & - \\
\hline Engländer & 1 & - & 1 & - & - \\
\hline Zusammen & 67 & 64 & 3 & 6 & 61 \\
\hline
\end{tabular}

A última tabela que analisamos, a número 5 , sobre o panorama geral do movimento de alunos dentro nos últimos anos (Übersicht über die Bewegung der Schülerzahl innerhalb der letzten Jahre) apresenta uma estatística do número total de alunos que frequentou os últimos 13 anos de ensino no Collegio Allemão, entre 1911 a 1923. Em 13 anos, foram registradas 861 matrículas com uma média de 66 alunos matriculados por ano. Dessas 861 matrículas, 91\% correspondiam a alunos de descendência alemã, e $9 \%$ não eram alemães (Nicht deutsche). Através dessa quinta tabela, acrescentamos que, entre 1917 e 1919, no período da Primeira Guerra, somente crianças de descendência alemã frequentaram o Collegio Allemão de Pelotas. No entanto, as crianças de outras etnias retornaram ao educandário a partir do ano de 1920. 
Tabela 5 - Vista Geral sobre o Movimento do Número Total de Alunos nos últimos anos (Übersicht über die Bewegung der Schülerzahl innerhalb der letzten Jahre) (RELATÓRIO ESCOLAR DO COLLEGIO ALLEMÃO DE PELOTAS, 1923, p. 16).

Überficht über die Bemegung der Schülerzahl innerhalb der legten Jahre.

\begin{tabular}{|c|c|c|c|c|}
\hline Jahr & Schulleiter & Deutsche & Nichtdeutsche & Zusammen \\
\hline 1911 & Gaile & 80 & 16 & 96 \\
\hline 1912 & " & 103 & 20 & 123 \\
\hline 1913 & ", & 89 & 9 & 98 \\
\hline 1914 & $"$ & 75 & 8 & 83 \\
\hline 1915 & $"$ & 68 & 3 & 71 \\
\hline 1916 & Heuer & 54 & 7 & 61 \\
\hline 1917 & $"$ & 51 & - & 51 \\
\hline 1918 & $"$ & 37 & - & 37 \\
\hline 1919 & , & 35 & - & 35 \\
\hline 1920 & 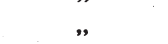 & 41 & 3 & 44 \\
\hline 1921 & 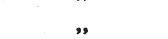 & 41 & 6 & 47 \\
\hline 1922 & $"$ & 46 & 2 & 48 \\
\hline 1923 & $\because$ & 63 & 4 & 67 \\
\hline
\end{tabular}

\section{Considerações finais...}

A cultura escolar constitui-se numa combinatória, não somente de práticas, mas de normas, que regem mentalidades, condutas e comportamentos, em uma instituição escolar. Em se tratando de uma instituição escolar teuto-brasileira, e urbana, há que acrescentar a presença da língua materna, ou seja, da língua alemã, inicialmente incentivada e posteriormente expressamente proibida. Tanto Julia (2001) como Viñao Frago (2000), reiteram a presença de regras e procedimentos com vistas à incorporação de conhecimentos e comportamentos expressados no cotidiano escolar. Nesse artigo, devido à quase inexistência de fontes, analisamos o Relatório Escolar do Collegio Allemão de Pelotas de 1923, importante ferramenta de regulação do discurso docente, no qual localizamos indícios de práticas escolares específicas desenvolvidas nesse educandário. Consideramos relevante o artigo primeiro dos Estatutos de 1915 que elucidam práticas diferenciadas que circulavam na cultura escolar, como por exemplo: a ratificação do ensino em dois idiomas, a preocupação com a preparação dos alunos para inserção na nova pátria, com vistas à garantia dos direitos de cidadão, os conhecimentos profissionais, a possibilidade do serviço militar no estrangeiro, as aspirações da instituição, a influência da igreja e da classe social.

Segundo Silva (2002, p. 268) o currículo de uma instituição educativa constitui-se no espaço onde se corporificam formas de conhecimento e de poder. Para esse autor, o currículo é "um dos locais privilegiados onde se entrecruzam saber e poder, representação e domínio, discurso e regulação. É também no currículo que se condensam relações de poder que são cruciais para o processo de formação de subjetividades sociais". Em resumo, currículo, poder e identidades sociais estão reciprocamente imbricados. De acordo com Chervel (1990) as disciplinas escolares presentes no currículo da instituição disciplinam o espírito ao se utilizarem de métodos e regras que traba- 
lham os diversos domínios do pensamento que contribuem para o entendimento da cultura produzida na e pela escola. A formação de subjetividades e identidades sociais, mais especificamente, a preservação de uma identidade étnica através do Collegio Allemão de Pelotas, evidencia-se no currículo do educandário e na constituição do corpo docente. Todos os professores têm nome de origem alemã, com exceção da professora de Português. Em relação à carga horária das disciplinas, o ensino estava predominantemente sob a responsabilidade de professores do sexo masculino, apesar de as professoras ocuparem um espaço docente significativo.

De acordo com Relatório Escolar de 1923, o colégio funcionou a partir do $3^{\circ}$ ano, atendendo a três classes de duplos. Por esta ocasião quatro docentes ministraram aulas no educandário. Consideramos relevante acrescentar que nessa década os professores eram formados em Pedagogia e, a língua alemã, apesar de apresentar o status de língua estrangeira (O REBATE,1920), continuava presente no currículo. As figuras referenciais docentes que permaneciam a maior parte do tempo com os alunos também eram professores alemães e/ou teuto-brasileiros e o ensino, segundo a aluna Johanna Ritter Ruge Hofmeister, o ensino, de fato, era ministrado predominantemente em língua alemã, priorizando os cuidados com a infância e a adolescência dos herdeiros desse grupo étnico. De forma recorrente, a língua alemã foi predominante no espaço didático, ocupando, aproximadamente $60 \%$ do currículo, em desvantagem da língua portuguesa, com $40 \%$. No entanto, apesar de a língua portuguesa ainda não ser hegemônica no ensino no Collegio Allemão de Pelotas em 1923, o escore de 40\% indicava a instalação gradativa do processo de Nacionalização do Ensino, que foi efetivado no final da década de 1930.

Todavia o fato de $60 \%$ do ensino ocorrer ainda em língua alemã é um indicador do objetivo desse grupo étnico de salvaguardar um capital cultural através da instituição escolar. De acordo com Rambo (1994, p.178), a língua alemã "representava o veículo transmissor, por excelência, dos valores e da tradição cultural”. Para Seyfert (1989, p. 141), "a sobrevivência da língua alemã é considerada essencial à própria sobrevivência do Deutschtum (Germanismo), e do próprio grupo étnico teuto-brasileiro". Disciplinas como Ensino Visual, Geometria, História Bíblica, Geografia, História Natural, História Geral, Canto e Trabalhos Manuais, ministradas em língua alemã, veicularam hábitos e tradições através das artes, da geometria, da religião, da história, da geografia e trabalhos manuais. Os fundamentos do bem cultural denominado germanismo contemplavam diversas áreas do conhecimento, tais como: as artes, o raciocínio abstrato, a memória do tempo, a situação no espaço e os trabalhos manuais, como $o$ artesanato para meninos e meninas.

No que diz respeito à análise do corpo discente do Collegio Allemão de Pelotas, através das tabelas: três, quatro e cinco, elucida-se a predominância de meninos sobre as meninas, numa proporção de $56 \%$ para $44 \%$. A maioria do corpo discente era composta por alunos teuto-brasileiros, atingindo $91 \%$ do total e, os alunos, os quais falavam o alemão como língua materna, perfaziam $95 \%$. A religião hegemônica era a evangélica, representada por $91 \%$ dos alunos. $\mathrm{E}$, ao longo de 13 anos, $91 \%$ dos alunos que frequentaram o Collegio Allemão de Pelotas eram descendentes de alemães. Neste sentido, a partir de análise do Relatório Escolar do Collegio Allemão de Pelotas de 
1923, conclui-se que práticas culturais específicas foram desenvolvidas no Collegio Allemão de Pelotas na década de 1920, em que um currículo exclusivo foi acionado por um corpo docente qualificado, visando à formação e à formatação de um corpo discente urbano, predominantemente teuto-brasileiro e evangélico, com vistas à continuidade de um patrimônio cultural - Deutschtum - ao institucionalizar a preservação da memória étnica conjugando-a par e par com os valores emergentes da cidadania brasileira.

Notas

${ }^{1}$ O Sínodo Rio-Grandense foi organizado em 1886, em São Leopoldo, sob a presidência do Dr. Wilhelm Rotermund que atuou como porta-voz das comunidades evangélicas luteranas encarregando-se de defender os interesses comuns das pessoas a ele filiados. "Suas funções abrangiam para além do enfoque religioso, principalmente o setor educacional” (TAMBARA, 1991, p. 399).

${ }^{2}$ Referia-se à Deutsche Spracheschule von Heuer, prefaciada em Pelotas, em dezembro de 1916, publicada pela editora Rotermund de São Leopoldo, já em segunda edição.

${ }^{3}$ Carlos Ritter, avô materno de Johanna Ritter Ruge Hofmeister, era proprietário da Cervejaria Ritter \& Irmão em Pelotas.

${ }^{4}$ Frederico Ruge, pai de Johanna Ritter Ruge Hofmeister, era fabricante de Charutos em Rio Grande.

\section{Referências}

ARENDT, I. Representações de Germanidade, Escola Professor na Allgemeine Lehrerzeitung für Rio Grande do Sul (Jornal Geral para Professores no Rio Grande do Sul). 2005. $292 \mathrm{f}$. Tese (Doutorado em História) - Programa de Pós-Graduação em História, Universidade do Vale do Rio dos Sinos, São Leopoldo, 2005.

CHERVEL, A. História das disciplinas escolares: reflexões sobre um campo de pesquisa. Teoria \& Educação, Porto Alegre, n. 2, p. 177-229, 1990.

DREHER, M. Igreja e Germanidade. São Leopoldo: Sinodal, 1984.

ESTATUTOS do Collegio Allemão de Pelotas, 1915.

FIORI, N. A. Germanismo pedagógico: contribuição ao entendimento do ensino elementar no século XIX. In: FIORI, N. A. (Org.). Etnia e educação: a escola "alemã" no Brasil e estudos congêneres. Florianópolis: Ed. da UFSC; Tubarão: Unisul, 2003. p. 233-258.

FONSECA, M.A. P. Estratégias para a Preservação do Germanismo (Deutschtum): Gênese e Trajetória de um Collegio Teuto-Brasileiro Urbano em Pelotas (1898-1942). 2007. 158f. Dissertação (Mestrado em Educação) - Programa de Pós-Graduação em Educação, Universidade Federal de Pelotas, Pelotas, 2007.

GARBOSA, L. Es Tönen die Lieder... Um olhar sobre o ensino da música nas escolas teuto-brasileiras da década de 1930 a partir de dois cancioneiros selecionados. 2003. 401f. Tese (Doutorado em Música-Educação Musical) - Programa de Pós-Graduação em Música, Universidade Federal da Bahia, Salvador, 2003.

GRÜTZMANN, I. O Carvalho entre palmeiras: representações e estratégias identitárias no germanismo. Revista do Programa de Pós-Graduação em História da Universidade do Vale do Rio dos Sinos. v. 7, n. 8. São Leopoldo: Unisinos, 2003. 
HEUER, R. Deutsche Spracheschule von Heuer. 2. ed. Verlag Rotermund \& Co.: São Leopoldo, Cruz Alta und Porto Alegre, 1916. (Prefaciado em Pelotas, Dezember 1916).

HOPPEN, A. Formação de professores evangélicos no Rio Grande do Sul (1909-1939). São Leopoldo: Editora do Autor, 1991.

JOHANNA RITTER RUGE HOFMEISTER. Entrevista. Pelotas, 4 janeiro. 2002.

JORNAL - O Rebate - Pelotas, 15 de janeiro de 1920.

JULIA, D. A cultura escolar como objeto histórico. Revista Brasileira de História da Educação. São Paulo, n. 1 p. 10-11, jan./jun. 2001.

KLUG, J. A escola teuto-catarinense e o processo de modernização em Santa Catarina: a ação da Igreja luterana através das escolas. (1871-1938). 1997. 261f. Tese (Doutorado em História Social) - Programa de Pós-Graduação em Ciências Humanas, Universidade de São Paulo, São Paulo, 1997.

KOLLING, N. B. Educação e escolas em contextos de imigração pomerana no Sul do Rio Grande do Sul - Brasil. 2000. 261f. Dissertação (Mestrado em Educação) - Programa de PósGraduação em Educação, Universidade Federal de Pelotas, Pelotas, 2000.

KREUTZ, L. O professor paroquial. Magistério e imigração alemã. Porto Alegre: UFRGS, 1991.

Material didático e currículo na escola teuto-brasileira do Rio Grande do Sul. São Leopoldo: Unisinos, 1994.

MEYER, D. Identidades traduzidas: cultura e docência teuto-brasileiro-evangélica no Rio Grande do Sul. Santa Cruz do Sul: Edunisc, 2000.

QUADROS, C. O discurso que produz a reforma: nacionalização do ensino e reforma educacional no Rio Grande do Sul (1937-1945). In: SIMPÓSIO NACIONAL DE HISTÓRIA, 24., 2007, São Leopoldo, RS. Anais do XXIV Simpósio Nacional de História - História e multidisciplinaridade: territórios e deslocamentos. São Leopoldo: Unisinos, 2007. CD-ROM.

RAMBO, A. B. A escola comunitária teuto-brasileira. São Leopoldo: Unisinos, 1994.

RELATÓRIO Escolar do Collegio Allemão de Pelotas, 1913 - Jahres=Bericht der Deutschen Schule zu Pelotas über das 14. Schuljahr 1913. Pelotas: Deutsche Wacht, 1914.

RELATÓRIO Escolar do Collegio Allemão de Pelotas, 1923. In Zum 25 jährigen Bestehen der Deutschen Schule zu Pelotas, 1898-1923. Rio Grande: Livraria Rio-Grandense, 1923.

RENK, V. E. A Educação dos imigrantes alemães católicos em Curitiba. Curitiba: ed. Champagnat, 2004.

RIOUX, J.-P.; SIRINELLI, J.-F. Pour une histoire culturelle. Paris: Seuil, 1997.

SEYFERT, G. Imigração e colonização alemã no Brasil. Boletim Informativo e Bibliográfico de Ciências Sociais (BIB). Rio de Janeiro, vol. 23, 1989.

SILVA, T.T. Educação pós-crítica e formação docente. In HYPOLITO, Á. M., VIEIRA, J. dos S., GARCIA, M. M. A. (Orgs.). Trabalho docente: formação e edentidades. Pelotas: Seiva, p. 257-269, 2002.

SOUZA. R. M. S. Deutsche Schule, a escola alemã de Curitiba: um olhar histórico (18841917). 2006. 289f. Tese (Doutorado em Educação) - Programa de Pós-Graduação em Educação, Universidade Federal do Paraná, Curitiba, 2006.

TAMBARA, E. A. C. A Educação no Rio Grande do Sul sob o Castilhismo. 1991. 600f. Tese 
(Doutorado em Educação) - Programa de Pós-Graduação em Educação, Universidade Federal do Rio Grande do Sul, Porto Alegre, 1991.

TAMBARA, E. A. C. A profissionalização, escola normal, feminização e feminilização: magistério Sul-Rio-Rio-Grandense de instrução pública-1880-1935. In HYPOLITO, Á. M., VIEIRA, J. S., GARCIA, M. M. A. (Orgs.). Trabalho docente: formação e identidades. Pelotas: Seiva, p. 67-97, 2002.

VIÑAO FRAGO, A. O espaço e o tempo escolares como objeto histórico. Contemporaneidade e Educação. Rio de Janeiro, ano v, n. 7, p. 93-100, jan./jun. 2000.

WILLEMS, E. Assimilação e populações marginais no Brasil. Rio de Janeiro: Nacional, 1940.

* Doutoranda em Educação pela Universidade Federal de Pelotas, Pelotas, Rio Grande do Sul, Brasil.

** Professor doutor da Universidade Federal de Pelotas, Pelotas, Rio Grande do Sul, Brasil.

\section{Correspondência}

Maria Angela Peter da Fonseca - Rua Prof. Dr. Araújo, 2149 Bloco F 401, CEP: 96020-360, Pelotas, Rio Grande do Sul - Brasil.

E-mail: mariangela@via-rs.net - elomar@pq.cnpq.br

Recebido em 25 de outubro de 2015

Aprovado em 02 de dezembro de 2015 